\title{
CARACTERIZAÇÃO FÍSICO-QUÍMICA DA BIOMASSA DE MILHO
}

\author{
V. P. CASARA ${ }^{1}$,L. R. BOHN ${ }^{1}$, A. P. DRESCH ${ }^{1}$, G. M. MIBIELLI ${ }^{1}$ e J. P. BENDER ${ }^{1}$ \\ ${ }^{1}$ Universidade Federal da Fronteira Sul, UFFS - Campus Chapecó \\ E-mail para contato: valeriacasara08@gmail.com
}

\begin{abstract}
RESUMO - O etanol atualmente produzido em nosso país é proveniente da fermentação do caldo de cana-de-açúcar e do melaço, substratos ricos em sacarose. A produção brasileira, no entanto, embora já bastante expressiva, pode vir a ter um aumento substancial quando a obtenção desse combustível for viabilizada também a partir de biomassa lignocelulósica. Nesse contexto, o resíduo da produção de milho aparece como destaque no cenário nacional e estadual. Em 2015, o estado de Santa Catarina produziu, em seus 465,4 mil hectares de área plantada, aproximadamente 2,5 milhões de toneladas deste resíduo. O desenvolvimento de um processo que disponibilize a glicose para uma posterior conversão em etanol, passa por uma adequada caracterização química da matéria-prima. Assim, neste trabalho, realizou-se a caracterização físico-química do caule e folha de milho, quanto à umidade, cinzas, extrativos e lignina insolúvel. O teor de umidade encontrado foi de $7,46 \%$ para o caule e 5,9\% para a folha. A porcentagem de cinzas variou de $2,63 \%$ para o caule e $5,78 \%$ para a folha. Logo, os valores encontrados para a porcentagem de extrativos mantiveram-se dentro da faixa literária e possuem concordância, pois o caule e a folha apresentaram maiores índices de extrativos, quando comparados com a palha.
\end{abstract}

\section{INTRODUÇÃO}

A alta dependência da sociedade em relação aos combustíveis fósseis e as projeções negativas quanto às reservas desses serviram de alerta para que fontes renováveis de energia começassem a ser desenvolvidas em ritmo acelerado. Biocombustíveis, como o biodiesel e o etanol, passaram a serem visualizados como alternativas potencialmente viáveis, reduzindo os riscos de falta de energia para o crescimento e desenvolvimento dos países.

Resíduo lignocelulósicos, como os obtidos durante a colheita do milho, podem possuir um alto teor de celulose e hemicelulose, polissacarídeos que a partir de sua hidrólise geram glicose e xilose, monômeros essenciais para produção de etanol 2G. Nacionalmente, a produção de milho ficou em torno de 53 milhões de toneladas no ano de 2011 e 55 milhões de toneladas no ano de 2012, de acordo com dados da Companhia Nacional de Abastecimento (2012), mostrando que entre as principais culturas de verão, o milho tem apresentado crescimento considerável ao longo dos anos e possui grandes áreas cultiváveis em diversas regiões do país. Portanto, existe grande geração de resíduos desse produto alimentício, como é o caso da folha, da palha e do caule do milho, que são na maioria dos casos subutilizados, mostrando-se promissores para a produção de etanol de segunda geração. Assim, a utilização dessa biomassa para a produção de bioetanol, perpassa, fundamentalmente, pelo conhecimento da composição físico-química da biomassa. 


\section{Metodologia}

\subsection{Obtenção e preparo da biomassa de milho}

A biomassa, caule e folha de milho, utilizadas nos experimentos foram obtidas nas áreas experimentais da Universidade Federal da Fronteira Sul - Campus Chapecó. Após a colheita do milho, a biomassa restante no campo foi coletada e armazenada em câmaras de refrigeração. Primeiramente a biomassa foi separada de materiais indesejáveis, como terra e restos de vegetação, restando apenas a biomassa lignocelulósica de milho, a qual foi separada em três frações: palha, caule e folha. Sendo a palha o material que envolve a espiga do milho, o caule é o material que fornece sustentação a planta e a folha é o material preso ao caule.

Realizada a separação, o material passou pela etapa de pré-secagem em estufa e redução de tamanho em moinho de facas, até a obtenção de partículas com tamanhos inferiores a 0,5 $\mathrm{mm}$, selecionadas através de uma peneira de $20 \mathrm{mesh}$, acoplada ao próprio equipamento. Em subsequência, realizaram-se as análises de umidade final, granulometria, teor de cinzas, extrativos e lignina solúvel.

\subsection{Análise granulométrica}

Para a determinação da distribuição do tamanho de partículas na biomassa, utilizou-se como referência o procedimento padrão NREL "Determination of Total Solids in Biomass" (Hames et al. 2005). Peneiras na série Taylor 9, 16, 30, 60 e 100 mesh foram utilizadas para a separação do material. Inicialmente pesaram-se as peneiras, que posteriormente são empilhadas na seguinte ordem, começando na parte inferior: a bandeja inferior, 100, 60, 30, 16 e 9 mesh. Em seguida, foi adicionado aproximadamente $80 \mathrm{~g}$ do material em análise na parte superior da série de peneiras e estas foram presas em um agitador eletromagnético, sendo agitadas durante $15 \mathrm{~min}$. Ao término do período, pesaram-se as peneiras para determinar a massa retida em cada uma delas.

Cabe salientar que foi utilizada, para a realização das análises de umidade, teor de cinzas, extrativos e lignina solúvel, a biomassa que passou pela peneira de 30 mesh. Ao término do experimento o material foi armazenado, em bolsas hermeticamente fechadas, dentro do freezer, seguindo o mesmo procedimento descrito por Rabelo (2010).

\subsection{Teor de umidade e sólidos totais}

Estufa: A determinação do teor de umidade da biomassa seguiu o procedimento padrão do NREL "Determination of Total Solids in Biomass" (Sluiter et al. 2005). O objetivo desta análise era medir a quantidade de água e outros componentes voláteis à $105^{\circ} \mathrm{C}$ presentes nas amostras. O teor de umidade da biomassa foi calculado pela Equação 1. Enquanto que o índice de sólidos totais da amostra pode ser calculado pela Equação 2.

$$
\% \text { umidade }=\left(1-\left(\left(M \_3-M \_1\right) /\left(M \_2-M \_1\right)\right)\right) \times 100
$$

Onde: $\mathrm{M}_{1}$ é a massa do béquer vazio, em $\mathrm{g} ; \mathrm{M}_{2}$ é a massa do béquer + amostra úmida, em $\mathrm{g}$ e $\mathrm{M}_{3}$ é a massa do béquer + amostra absolutamente seca, em $\mathrm{g}$. 


\section{$\%$ sólidos totais $=100-\%$ umidade}

Infra-vermelho: Para a determinação do teor de umidade por infravermelho utilizou-se o equipamento da marca GEHAKA, modelo IV2500.

\subsection{Teor de cinzas}

Com a finalidade de quantificar o material inorgânico na biomassa, estrutural ou extraível, como parte da composição total, utilizou-se o procedimento padrão NREL "Determination of Total Solids in Biomass" (Sluiter et al. 2005). Primeiramente determinouse o teor de umidade das amostras, como descrito no item 2.3. Tal umidade foi descontada da massa da amostra pesada, para a execução do experimento. Para a determinação do teor de cinzas utilizaram-se cadinhos de porcelana de $50 \mathrm{~mL}$, devidamente inumerados e pesados em uma balança analítica. Pesou-se cerca de 1,00 g do material, descontando o teor de umidade, nos cadinhos previamente pesados. Realizou-se a carbonização do mesmo em mufla a $800^{\circ} \mathrm{C}$ por 20 min. Repetiu-se a calcinação por mais 15 min para se verificar a constância do peso, efetuaram-se as análises em triplicata (Rabelo, 2010). Para o cálculo do teor de cinzas utilizou-se na Equação 3.

$$
\text { \%cinzas=((M_3-M_1)/(M_2-M_1 ) }) \times 100
$$

Onde: $\mathrm{M}_{1}$ é a massa do cadinho vazio, em $\mathrm{g} ; \mathrm{M}_{2}$ é a massa do cadinho vazio + massa da biomassa descontando o teor de umidade, em $\mathrm{g} ; \mathrm{M}_{3}$ é a massa do cadinho com cinzas, em g.

\subsection{Teor de extrativos}

Desempenhou-se os experimentos baseando-se nos procedimentos padrões NREL "Determination of Total Solids in Biomass" (Sluiter et al. 2005) e na norma TAPPI T "Solvent Extractives in Biomass" (TAPPI,1996). Determinou-se inicialmente o teor de umidade de acordo com o procedimento descrito no item 2.3. Adicionou-se aproximadamente 4,00 g da amostra, descontando o teor de umidade, ao cartucho de extração tendo sua massa devidamente anotada. Após a montagem do extrator, o cartucho preenchido pela biomassa foi introduzido no tubo de extração do soxhlet. Logo, adicionou-se $200 \mathrm{~mL}$ de água destilada em cada balão do extrator juntamente com pérolas de vidro. Colocam-se os balões no extrator e ligou-se o aquecimento do mesmo para que o processo de sifonações inicia-se. A extração ocorreu até que o solvente em torno do cartucho se tornou incolor. Para o cálculo do teor de extrativos recorre-se a Equação 4.

$$
\% \text { extrativos=((M_1-M_2)/M_1 }) \times 100
$$

Onde: M1 é a massa da biomassa descontando o teor de umidade, em g; M2 é a massa da biomassa livre de extrativos, em $\mathrm{g}$.

\subsection{Teor de lignina insolúvel}

Para a determinação da lignina insolúvel, realizou-se primeiramente uma hidrólise ácida concentrada, onde pesou-se aproximadamente $0,30 \mathrm{~g}$ de cada amostra, descontando o teor de umidade, em tubos de ensaio devidamente etiquetados. Adicionou-se 3,00 mL de ácido sulfúrico a $72 \%(\mathrm{~m} / \mathrm{m})$ em cada tubo. Posteriormente, os tubos foram incubados em banho 
termostático a $30^{\circ} \mathrm{C}$ por $1 \mathrm{~h}$. Usou-se um bastão de vidro para agitar as amostras a cada 5-10 min, sem remover os tubos do banho. Logo, no processo de hidrólise ácida diluída, depois de decorrido o tempo da hidrólise ácida concentrada, removeu-se os tubos do banho e transferiuse o conteúdo quantitativamente para erlenmeyers de $250 \mathrm{~mL}$, utilizando para isso, $84 \mathrm{~mL}$ de água destilada, sendo a concentração ácida do meio diluída para 4\%. Preparou-se um branco com ácido sulfúrico a 4\%. Para a completa hidrólise dos oligômeros, fecharam-se os erlenmeyers com papel alumínio e elásticos e os colocou em uma autoclave, por $1 \mathrm{~h} \mathrm{a} 121^{\circ} \mathrm{C} \mathrm{e}$ 1,1 bar. Após a descompressão da autoclave, os frascos foram retirados e resfriados à temperatura ambiente antes de remover o papel alumínio.

Os hidrolisados ácidos foram filtrados em funil utilizando-se papéis de filtro, em seguida, o papel filtro juntamente com os sólidos retidos foram transferidos para Placas de Petri e encaminhados para estufa a $40^{\circ} \mathrm{C}$ até massa constante (Aproximadamente $40 \mathrm{~min}$ ). Para que não houvesse uma superestimação dos dados de lignina insolúvel, o teor de cinzas determinado para cada material, segundo o método já explanado, foi descontado nos cálculos. Como demonstra a Equação 5.

\% lignina insolúvel l=((M_2/M_1 $) \times 100)-\%$ cinzas

Onde: M1 é a massa da biomassa utilizada na hidrólise descontando o teor de umidade, em g; M2 é a massa da lignina insolúvel seca, em g; \% cinzas: teor de cinzas, determinado segundo a Equação 3.

\section{RESULTADOS E DISCUSSÕES}

\subsection{Granulometria}

Após o processo de secagem, separação inicial e moagem, em moinhos de faca, realizou-se a análise granulométrica das frações caule e folha, passando-se o material por peneiras da Série Taylor, com malhas de 9, 16, 30, 60 e 100mesh, equivalentes a uma abertura de malha de $2,1,0,6,0,297$ e $0,15 \mathrm{~mm}$, respectivamente. O percentual de amostra retida em cada peneira é apresentado na Figura 1.

Figura 1 - Percentual das frações de biomassa retida em cada peneira

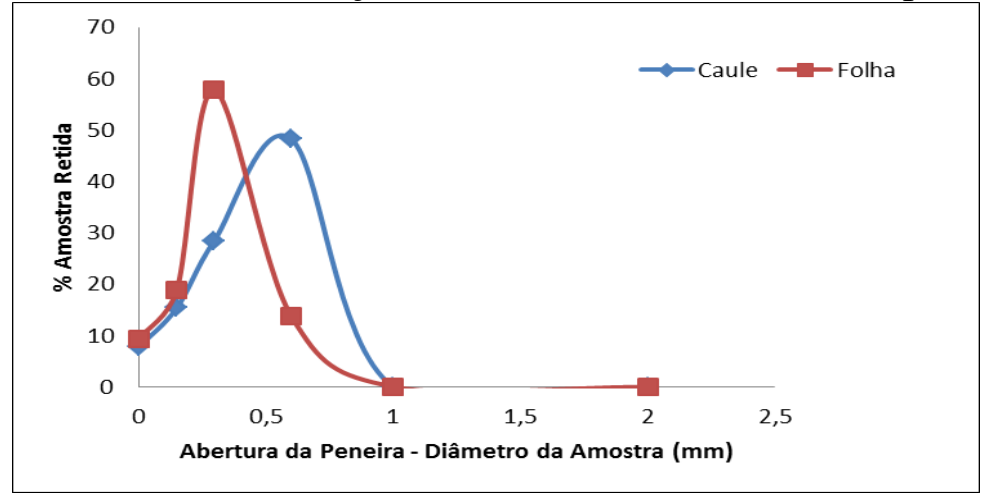

Pode-se observar, por meio da Figura 1, que o caule e a folha de milho, após o processo de moagem pelo moinho de facas, apresentam uma distribuição de tamanho de partículas entre 0 e $1 \mathrm{~mm}$, sendo que o tamanho médio das partículas foi de $0,44 \mathrm{~mm}$ para o caule e 
0,32mm para a folha. Ambas as frações de biomassa apresentaram uma baixa dispersão do tamanho das partículas.

Diante disso a partir do estudo realizado com as duas biomassas, caule e folha de milho, extraídas do campus da Universidade Federal da Fronteira Sul foi possível avaliar, que a folha apresentou diâmetro superior a $0,297 \mathrm{~mm}$ (60 mesh). Já o caule apresentou partículas maiores, sendo na sua maioria partículas acima de $0,6 \mathrm{~mm}$ (30 mesh) de diâmetro. Observando-se heterogeneidade no tamanho das fibras.

\subsection{Teor de umidade e sólido totais}

O teor de umidade e de sólidos totais das frações caule e folha da biomassa de milho, utilizando duas metodologias (estufa e infravermelho) são apresentados na Tabela 1.

Tabela 1 - Teor de umidade das frações caule e folha da biomassa de milho utilizando duas metodologias de secagem, estufa e infravermelho.

\begin{tabular}{lcccc} 
& \multicolumn{2}{c}{ Estufa } & \multicolumn{2}{c}{ Infravermelho } \\
\cline { 2 - 5 } & \% Umidade & \% Sólidos & \% Umidade & \% Sólidos \\
\hline Caule & 7,46 & 92,54 & 7,43 & 92,57 \\
Folha & 5,90 & 94,10 & 6,30 & 93,70 \\
\hline
\end{tabular}

Não houve discordância significativa em relação aos dois métodos. Logo, o teor de umidade pode ser considerado aceitável, uma vez que os valores foram a baixo e/ou equivalentes aos apresentados pela literatura de caracterização de materiais lignocelulósicos, que apontam valores inferiores a $10 \%$. Isso é uma característica importante, pois o poder calorífico de matérias-primas lignocelulósicas é inversamente proporcional ao teor de água presente nos mesmos. Fator que pode interferir direta ou indiretamente nos parâmetros de prétratamento, pois altos valores de umidade demandam mais energia para etapa de secagem que antecipa a degradação térmica da biomassa (Santos, 2014).

\subsection{Análise da composição química}

O teor de cinzas, extrativos e lignina insolúvel, para as frações de biomassa em estudo, são apresentados na Tabela 2.

Tabela 2 - Composição química das frações caule e folha de milho

\begin{tabular}{|c|c|c|}
\hline Composição química (\%) & Caule & Folha \\
\hline Cinzas & 2,63 & 5,78 \\
\hline Extrativos & 25,36 & 25,46 \\
\hline Lignina insolúvel & 4,35 & 7,63 \\
\hline
\end{tabular}

Os teores de cinzas obtidos para as frações de caule e folha são superiores aos citados por Souza et al. (2005), que apresenta valores entre 1,8 a 1,98 \% de inorgânicos no bagaço de sorgo. E diferem do teor de cinza do bagaço da cana-de-açúcar que varia entre 2 e $3 \%$ (Banerjee et al. 2002). A baixa concentração de inorgânicos, tona favorável o processo de utilização da biomassa, pois ao final da produção não serão gerados novos volumes de resíduos. 
Quanto aos extrativos, Salazar et al. (2005) relataram para a palha de milho 28,53\% de extrativos, já Luana (2010) encontrou uma porcentagem de 5,85 para o mesmo material, 10,51 para a folha e 11,31 para o caule. Os valores constatados no estudo para os extrativos estão dentro da faixa literária e apresentam concordância, pois o caule e a folha apontaram maiores índices de extrativos, quando comparados com a palha. Isso se deve ao fato de que a folha e o caule possuem maiores índices de clorofila, pigmento verde que absorve a energia da luz solar, e seiva, líquido que circula nas plantas vascular formado principalmente por glicose e sais minerais.

\section{CONCLUSÃO}

Todas as etapas envolvidas no processo de produção de etanol por meio de biomassas

lignocelulósicas, com o intuito de reaproveitamento dos resíduos, exige inicialmente o conhecimento das variações físico-químicas do mesmo.

Os resultados mostraram que o resíduo lignocelulósico, proveniente do milho, é viável física e quimicamente frente ao volume gerado nas lavouras. Tornando-se possível o desenvolvimento de um processo que disponibilize a glicose para uma posterior conversão em etanol.

\section{REFERENCIAS}

BANERJEE, R.; PANDEY.Bio-industrial applications of sugarcane bagasse: a technological perspective. International Sugar Journal, Glamorgan, v.104, n.1328, 2002.

HAMES, B., RUIZ, R., SCARLATA, C., SLUITER, A., SLUITER, J., TEMPLETON, D. Preparation of Samples for Composition Analysis. Nat. Ren. Energy Lab., v. 1-12, 2005.

LUANA E. R. P. Produção e avaliação de briquetes de resíduos lignocelulósicos. Dissertação do Programa de Pós-Graduação em Ciência e Tecnologia da Madeira. Universidade Federal de Lavras. Lavras - MG. 2010, p. 83.

RABELO, S. C. Avaliação e otimização de pré-tratamentos e hidrólise enzimática do bagaço de cana-de-açúcar para a produção de etanol de segunda geração. Tese Doutorado em Engenharia Química. Universidade Estadual de Campinas - Unicamp, Faculdade de Engenharia Química, Programa de Pós-Graduação em Engenharia Química. Campinas SP. 2010.

SALAZAR, R. F. S.; SILVA, G. L. P.; SILVA, M. L. C. P. Estudo da composição da palha de milho para posterior utilização como suporte na preparação de compósitos. Faculdade de Engenharia Química de Lorena - FAENQUIL. Lorena - SP. 2005, p.7.

SLUITER, A., RUIZ, R., SCARLATA, C., SLUITER, J., TEMPLETON, D. Determination of total solids in biomass. Nat. Ren. Energy Lab., v. 1-6, 2005.

SANTOS, M. S. R. Estudo de pré-tratamentos de palha e sabugo de milho visando a produção de etanol 2G. Dissertação de Mestrado. Universidade Federal de Alagoas - UFAL. Maceió - AL. 2014, p. 76.

SOUZA, C.C et al. Produtividade Do Sorgo Granífero Cv. Sacarino E Qualidade De Produtos Formulados Isoladamente Ou Combinados Ao Caldo De Cana-DeAçúcar. Ciência e Tecnologia, v25. Campinas, 2005. 